\title{
East Meets West: A Meta-Analytic Investigation of Cultural Variations in Idealism and Relativism
}

\author{
Donelson R. Forsyth \\ Ernest H. O’Boyle, Jr. \\ Michael A. McDaniel
}

\begin{abstract}
Ethics position theory (EPT) maintains that individuals' personal moral philosophies influence their judgments, actions, and emotions in ethically intense situations. The theory, when describing these moral viewpoints, stresses two dimensions: idealism (concern for benign outcomes) and relativism (skepticism with regards to inviolate moral principles). Variations in idealism and relativism across countries were examined via a meta-analysis of studies that assessed these two aspects of moral thought using the ethics position questionnaire (EPQ; Forsyth, Journal of Personality and Social Psychology 39, 175-184, 1980). This review identified 139 samples drawn from 29 different countries, for a total sample of 30,230 respondents, and concluded that (a) levels of idealism and relativism vary across regions of the world in predictable ways; (b) an exceptionist ethic is more common in Western countries, subjectivism and situationism in Eastern countries, and absolutism and situationism in Middle Eastern countries; and (c) a nation's ethics position predicted that country's location on previously documented cultural dimensions, such as individualism and avoidance of uncertainty (Hofstede, Culture's Consequences: International Differences in WorkRelated Values, 1980). Limitations in these methods and concerns about the validity of these cross-cultural conclusions are noted, as are suggestions for further research using the EPQ.
\end{abstract}

KEY WORDS: idealism, relativism, meta-analysis, systematic review, cross-cultural differences, international ethics

ABBREVIATIONS: EPT: ethics position theory; EPQ: ethics position questionnaire; TSV: traditional/secularrational values; SSV: survival/self-expression values; PDI: power distance index; IDV: individualism; MAS: masculinity; UAI: uncertainty avoidance; LTO: long-term orientation
People, the world over, agree when judging the morality of particularly egregious and commendable actions. In most societies people would suffer moral condemnation if they deliberately lied to others so as to take advantage of them; harmed or killed innocent children; took valuables from other people; turned away from those who would be injured or killed if help is not given; failed to keep promises they swore they would honor. Conversely, most societies, with somewhat more variance, consider persons to be due moral acclaim if they donate personal resources to others who are in need, see that others are treated fairly in civil and legal proceedings, and protect others from danger and adversity (Abratt et al., 1992).

This cross-cultural consensus is lost, however, when the discussion turns to less clear-cut issues. U.S. students morally condemned employees of an auto repair shop who lied to their customers about the work they performed, but Russian business students were far more lenient in their moral appraisals (Ahmed et al., 2003). Many Westerners violate copyright laws, but they recognize that copying protected material is wrong. Consumers in Hong Kong do not agree: they see such actions as illegal, but not immoral (Chan et al., 1998). In Haiti and Thailand, requesting monetary compensation for smoothing out a business transaction is standard practice; in the U.S. soliciting and accepting a bribe would cross a moral boundary (Kaikati et al., 2000). Austrians in one survey did not think that a male boss who only promotes women who agreed to see him socially is acting immorally, but Americans considered such behavior to be unethical (Davis et al., 1998). In the U.S. it is common practice for employees to evaluate their bosses; in other 
countries, such practices would be considered at best discourteous, and at worst immoral.

The goals for this article are theoretical, empirical, and practical ones. In terms of theory, we seek to develop a partial explanation for cultural variations in morality and moral judgment. This conceptual framework, which we label ethics position theory (EPT), is based on Forsyth's (1980) distinction between an ethics of idealism and an ethics of relativism. Idealism, ideologically, pertains to one's concern for minimizing negative consequences and maximizing gain, particularly for others. Relativism, the second ideological dimension, describes one's emphasis on moral rules and principles when making decisions about right and wrong. We suggest that these two dimensions, which have been used with some success to describe individual differences in morality, may also provide a way of classifying and contrasting consistencies in a culture's perspective on ethics as well as other cultural dimensions (Hofstede, 1980).

Empirically, we seek to summarize statistically the results of prior studies that have examined these two dimensions of ethics worldwide. Investigators have been studying diligently variations in ethics across contexts and cultures for a number of years, and in many cases they have used Forsyth's (1980) ethics position questionnaire (EPQ) to better understand the degree to which a culture's constituents base their moral pronouncements on idealism and relativism. It remains, however, to step back from these specific findings, and review them thoroughly to identify the general conclusions they support or disconfirm. Our second goal of this article, then, is to report the results of a meta-analysis of over 80 studies that measured differences in idealism and relativism in studies of residents in Eastern, Middle Eastern, and Western nations.

Practically, we hope that this review and the EPT, more generally, offer insight into a common conundrum facing people who conduct multinational transactions: misunderstandings and confusions about what is viewed as morally acceptable and even laudable and what is viewed as morally wrong and condemned. As continuing globalization brings people from different cultures together in shared enterprises they often find that they do not see eyeto-eye in their moral appraisals. All would agree that international business dealings are shaped, in part, by ethics, but what is considered moral differs to some extent from one culture to another. The current work offers a means of conceptualizing and simplifying those variations by considering how specific moral practices reflect a culture's orientation with regards to idealism and relativism.

\section{Ethics position theory (EPT)}

Reasonable people often disagree with one another when discussing questions of ethics, and theorists and researchers have traced these variations in judgments back to a variety of sources. Kohlberg (1976) suggested that the cognitive changes that occur as people learn more about ethical choices prompt shifts from simpler, punishment-oriented thinking to more principled thinking. Gilligan and her colleagues (e.g., Brown et al., 1995) theorized that the sex-linked experiences of men and women result in them judging the same action differently, with men more likely to apply an ethics of justice, whereas women would consider the situational context. Hunt and Vitell (1986, 1993) identified a number of personal factors, including religion, value systems, strength of moral character, and sensitivity to moral issues, in their model of moral decision making. Lee and Ashton (2004) suggested that ethicality ranks alongside introversion, conscientiousness, and stability as one of the cornerstones of personality, and individuals will differ in their moral actions and judgments depending on their modesty, greediness, and concern for fairness. Dahlsgaard et al. (2005) suggested that individuals vary in virtuousness, with the result that those with a larger share of human strengths will respond differently than those with weaker moral characters.

Ethics positions theory (EPT) similarly suggests that people's reactions in morally toned situations can be traced to variations in their intuitive, personal moral philosophies (Forsyth, 1980). Just as philosophers who specialize in the nature of moral thought often disagree when discussing the moral goodness of a particular action - for example, Immanuel Kant, famously condemned a lie told even with the best of intentions, whereas Jeremy Bentham favored the telling of untruths so long as they benefited the greatest number - EPT suggests that individuals are intuitive moral philosophers, who base their 


\section{Ethics Position Theory}

judgments of right and wrong on a personal ethics position they have developed over a lifetime of experience in confronting and resolving moral issues.

These intuitive moral theories likely contain a number of unique and idiosyncratic elements, but concern for consequences and concern for principles are two nomothetic regularities that appear consistently across most people. EPT labels the consequences dimension idealism, for the focal point of this dimension is the impact of the action on people's welfare. Highly idealistic individuals "assume that desirable consequences can, with the 'right' action, always be obtained" (Forsyth 1980, p. 176). Those who are less idealistic, in contrast, pragmatically assume that in some cases harm is unavoidable, and that one must sometimes choose between the lesser of two evils. The second distinction drawn in EPT, relativism, pertains to one's emphasis on moral principles as guides for determining what is right and wrong. Highly relativistic individuals' moral judgments are configural, for they base their appraisals on features of the particular situation and action they are evaluating. People who are low in relativism, in contrast, have more cognitive faith in moral principles, norms, or laws and use those principles to define for them what is right and what is wrong (Forsyth, 1980, 1985, 1992, 1994).

Forsyth (1980) developed the EPQ to assess idealism and relativism. The idealism scale includes such items as "A person should make certain that their actions never intentionally harm another even to a small degree" and "If an action could harm an innocent other then it should not be done." The relativism scale includes items like "Different types of moralities cannot be compared as to rightness" and "What is ethical varies from one situation and society to another." Respondents indicate degree of agreement with each item using a scale that ranges from 1 (completely disagree) to 9 (completely agree). The scales are orthogonal to one another and are only slightly correlated with social desirability (Forsyth and Nye, 1990; Forsyth et al., 1988).

Ethics positions

Ethics position theory assumes that a person's degree of idealism and relativism determines their ethical ideology, and identifies the four distinct ethics positions listed in Table I (Forsyth, 1980). Situationists prescribe inspection of the situation - particularly the consequences both intentionally and accidentally produced - in reaching a contextually appropriate moral evaluation. Situationism corresponds to such skeptical philosophies as situation ethics and value pluralism. Subjectivists, like situationists, reject moral rules, but they recognize that negative consequences are sometimes unavoidable. Since such individuals describe their moral decisions as subjective judgments that cannot be made on the basis of moral absolutes or the extent to which the action benefits others their viewpoint parallels an egoistic moral philosophy.

TABLE I

Four ethics positions

\begin{tabular}{lll}
\hline Idealism & \multicolumn{1}{c}{ Relativism } & \multicolumn{1}{c}{ High } \\
\cline { 2 - 3 } Low & $\begin{array}{l}\text { Exceptionism: Individuals should act } \\
\text { in ways that are consistent with } \\
\text { moral rules, but one should remain } \\
\text { pragmatically open to exceptions to } \\
\text { these rules } \\
\text { Absolutism: } \text { Individuals should act in } \\
\text { ways that are consistent with moral } \\
\text { rules, for doing so will in most cases } \\
\text { yield the best consequences for all } \\
\text { concerned }\end{array}$ & $\begin{array}{l}\text { Subjectivism: Individuals' personal } \\
\text { values and perspectives should guide } \\
\text { their moral choices, rather than } \\
\text { universal ethical principles or desire } \\
\text { to achieve positive consequences }\end{array}$ \\
& $\begin{array}{l}\text { Situationism: } \text { Individuals should act } \\
\text { to secure the best possible conse- } \\
\text { quences for all concerned even if } \\
\text { doing so will violate traditional rules } \\
\text { about ethics }\end{array}$
\end{tabular}


Absolutists believe that one should strive to produce positive consequences (high idealism) but at the same time maintain strict adherence to general moral principles (low relativism). These individuals condemn actions that harm people and violate fundamental moral absolutes. Such an outlook corresponds to a system of ethics that is grounded in rules, such as Kantian deontology and the Judeo-Christian conception of moral commandments. Exceptionists also endorse the value of moral principles, but their low idealism prompts them to pragmatically balance the positive consequences of an action against the negative consequences of an action. Their outlook, thus, corresponds to a moral philosophy based on rule-utilitarianism: moral principles are useful because they provide a framework for making choices and acting in ways that will tend to produce the best consequences for all concerned.

\section{Ethics across cultures}

Researchers have used, with some success, the EPQ to predict how people respond to ethical challenges in a variety of business situations. These studies suggest that, in general, idealism is associated with firm moral convictions, whereas relativism suggests ethical leniency. Douglas and Wier (2005), for example, found that idealism was negatively related to questionable budgetary practices (slack creation behavior), but relativism was positively correlated with such practices. Tsai and Shih (2005) report that managers who were more idealistic reported feeling greater role conflict, whereas increases in relativism went hand-in-hand with reduced conflict. Karande et al. (2002) concluded that idealism was related to a strong sense of corporate values, but relativism was negatively related to corporate ethics. Barnett et al. (1998), after classifying a national sample of marketing professions into the four categories described by the EPQ, found that absolutists were the most negative when judging hypothetical indiscretions particularly in comparison to subjectivists.

These tendencies hold, to some extent, across different cultural contexts. Al-Khatib, Vitell, and other investigators, in a series of studies conducted in different nations, have explored how consumers respond when they benefit at the expense of others or as a result of morally questionable or illegal activities. This work finds some differences among the nations investigated, but in studies conducted in Egypt (Al-Khatib et al., 1995), Romania (Al-Khatib et al., 2004), the U.S. (Vitell and Paolillo, 2003), Saudia Arabia (Al-Khatib et al., 2005), Austria (Rawwas, 1996) and Japan (Erffmeyer et al., 1999) idealistic individuals tend to respond negatively to situations where consumers take advantage of a retailer's error, whereas relativists are more lenient. Al-Khatib et al. (1995), for example, found that Egyptians who were more idealistic reacted more negatively to situations, where some might benefit but others are harmed, but individuals who endorsed a more relativistic ethics position found such situations to be more tolerable.

Some work, however, suggests that levels of idealism and relativism, and their relationship to moral reactions, vary across cultures. Deering (1998), in a comparison of British and American pre-service teachers, found higher levels of idealism and relativism among the British. Americans scored lower on the EPQ scales when compared to residents of Australia (Singhapakdi et al., 2001), Thailand (Singhapakdi et al., 1994), Malaysia (Axinn et al., 2004), and Spain (Vitell et al., 2003). Davis et al. (1998) found a predominance of nonrelativists (absolutists and exceptionists) among the Americans they studied, but a higher percentage of the participants from Indonesia were subjectivists. Al-Khatib et al. (2005) report that consumers in Saudi Arabia were more idealistic than those in Kuwait or Oman. Rawwas et al. (1994), noting that social stability and internal conflict might influence ethics positions, discovered that residents of Lebanon were less idealistic and more relativistic than residents of Egypt, and they could predict differences in the leniency of moral pronouncements by considering these variations.

\section{The current study}

The current project extended prior work on the cultural variations in ethics positions by summarizing the existing state of research using meta-analysis. Rather than collecting additional data from individual subjects or review prior work qualitatively, we instead identified, reviewed, and analyzed the findings reported in previous studies that used the 


\section{Ethics Position Theory}

EPQ to assess participants' degree of relativism and idealism. Since researchers have used the EPQ in a number of different nations, an objective review of that literature might yield general conclusions about cross-cultural differences in relativism and idealism.

We based our hypotheses on more general theoretical analyses of how cultures compare in terms of overall ethics orientations, and drew a broad distinction between Eastern, Middle Eastern, and Western cultures. From the outset, it must be admitted that the religions and philosophies of the nations in these geopolitical clusters vary from one another in enumerable ways, so any generalizations will fail to do justice to the unique features of each culture's traditions and perspectives (Koehn, 1999). This caveat not withstanding, and given evidence reported in prior research, we nonetheless expected that levels of idealism and relativism would differ among these three regions.

With regards to idealism, we predicted that the well-documented individualism of Western nations, relative to the East, suggested that the nations in this region would adopt less idealistic moral philosophies. Individualism is a tradition or worldview based on each individual's independence and uniqueness. This doctrine assumes people are autonomous, and must be free to act and think in ways that they prefer, rather than submit to the demands of the group. Collectivism, in contrast, puts the group and its goals before those of the individual members. This cultural orientation stresses the fundamental importance of relationships, with moral obligations based on respect, trust, and a sense of community rather than general, cross-situational moral dictates (Bellah et al., 1985). Collectivism implies idealism, at least as idealism is defined by the items on the EPQ (e.g., "The dignity and welfare of people should be the most important concern in any society," Forsyth, 1980, p. 178).

Turning to reliance on moral principles, we predicted that Eastern nations would be more relativistic than Western ones. Eastern philosophies, rooted in cultural traditions of Shintoism, Hinduism, Zen, Buddhism, and Taoism, tend to be more contextual, relational, and dynamic but less dualistic and principle focused in comparison to Western, Judeo-Christian philosophies. Buddhism, for example, is the dominant spiritual tradition in many parts of Asia, and despite the clear direction of its teachings it maintains that what is right and wrong, morally, is a decision that must be made in a specific context. Buddhism offers suggestions for making moral choices, but its principles are not crosssituational and cross-temporal rules that define the morally good. Eastern philosophies stress change rather than constancy, as illustrated in the ancient Chinese symbol called T'ai-chi T'u, or Yin/Yang. The notion of Yin/Yang suggests that what is wrong can be transformed into what is right, and that both good and evil contain within them elements of the other. This committed relativism results in a general mistrust in conventional knowledge and reasoning since the human intellect can only dimly comprehend the spiritual world (Tan, 2002; Xing, 1995).

We also predicted that Middle Eastern nations would be more idealistic than Western nations, but less relativistic than Eastern ones. Residents of Middle Eastern nations, such as Saudi Arabia, Lebanon, and Egypt, are primarily Muslim, and they are more likely to adopt the ethical principles and perspectives of the teachings of the Quran and the Sunnah, which are the records of the teachings of the Prophet Muhammad. Islam urges strict compliance with the moral dictates of the Quran, and so those who accept this faith will tend to be less rather than more relativistic (Abeng, 1997). Islam also enjoins its followers to provide service to and care of their community. Powerful social mores that govern interactions within Islamic society are based, in part, on the value placed on helping others, forgiveness, compensating others for their losses, and service to the community at large (Marta et al., 2003). These cultural tendencies suggested that individuals from Middle Eastern countries will endorse moral philosophies that are more idealistic but less relativistic.

$H_{1}$ : Nations will differ in levels of idealism and relativism, such that $\left(\mathrm{H}_{1 \mathrm{~A}}\right)$ residents of Eastern and Middle Eastern nations will be more idealistic than those in West; and $\left(\mathrm{H}_{1 \mathrm{~B}}\right)$ residents of Eastern nations will more relativistic than those in Western and Middle East nations.

In addition to these regional differences in overall idealism and relativism, we also predicted that the nations within the three regions would differ in their ethics positions within the 4-fold EPT typology. If, as $\mathrm{H}_{1}$ suggests, western countries are less idealistic 
$\left(\mathrm{H}_{1 \mathrm{~A}}\right)$ and less relativistic $\left(\mathrm{H}_{1 \mathrm{~B}}\right)$, then surveys of those nations should find more exceptionists than other ethics positions. If, in contrast, eastern countries tend to be more relativistic and idealistic, then the dominant ethics ideology of those nations should be situationism. Relatively more Middle Eastern peoples should be absolutists, since they tend to be low in relativism and high in idealism.

$\mathrm{H}_{2}$ : Regions will differ in the proportion of residents that adopt each ethics position: $\left(\mathrm{H}_{2 \mathrm{~A}}\right)$ relatively more individuals in Western nations will endorse an exceptionist ethics position (low idealism and low relativism); $\left(\mathrm{H}_{2 \mathrm{~B}}\right)$ those in Eastern nations will tend to be situationists; and $\left(\mathrm{H}_{2 \mathrm{C}}\right)$ residents of Middle Eastern nations will tend to be absolutists.

These predicted variations in ethics positions across nations and regions should be associated with cultural differences in values, practices, and social norms. Studies of different cultures indicate that each one has unique and idiosyncratic features, but that cultures can be compared and contrasted in terms of a few key dimensions. Some cultures, for example, stress power differentials between groups more so than others, whereas others emphasize individuals more than collectives. Specifically, we predicted that a nation's level of idealism and relativism would be linked to other nation-level indices of cultural values, including Hofstede' (1980) Cultural Dimensions and Inglehart's (1997) Dimensions of World Values.

For the Hofstede (1980) cultural dimensions, we expected that idealism would be associated with the masculinity (MAS) dimension, and relativism would be related to individualism and uncertainty avoidance (UAI). Hofstede suggested that cultures that score low in masculinity embrace prosocial, caring values that are consistent with family and relationships, whereas cultures that score higher in masculinity stress competition, goal-striving, and personal success over concern for others. These differences parallel highs and lows in idealism. With regards to relativism, we hypothesized that the collectivistic cultures of the Eastern region of the world would tend to be also relativistic, and so expected that relativism would be negatively associated with individualism. We also expected that relativistic nations would be lower in UAI. As House and
Javidan (2004) explained, individuals living in a culture that is high in UAI "actively seek to decrease the probability of unpredictable future events that could adversely affect the operation of an organization or society" (p. 12), and a more strict moral code may be one means of reducing that unpredictability. Individuals in cultures that are not uncertainty averse, in contrast, would be more likely to tolerate unexpected actions on the part of members, even when those actions are inconsistent with expectations based on what is considered moral or immoral (Scholtens and Dam, 2007). Such cultures, which in Pelto's (1968) terms would be loose rather than tight, should be characterized by higher levels of relativism.

We also examined the relationship between idealism and relativism and the cultural dimensions identified by Inglehart's (1997) and Inglehart and Baker (2000) analysis of responses to the World Values Survey of 65 societies. Inglehart found consistent differences among countries along a traditional/secular-rational values (TSV) dimension and a Survival/Self-expression values (SSV) dimension. Inglehart and Baker (2000, p. 25) wrote: "the people of traditional societies have high levels of national pride, favor more respect for authority" and "accept national authority passively." They "emphasize social conformity rather than individualistic striving [and] believe in absolute standards of good and evil." Cultures with low scores on the TSV dimension also tended to be ones where the populace adopts traditional religious beliefs, such as believing in God and Hell and gaining strength from their religious beliefs. Given that religiosity - particularly in samples of Westerners - is related to both idealism and relativism (e.g., Barnett et al., 1996; Singhapakdi et al., 2000; Vitell and Paolillo, 2003), we predicted that idealism would be negatively associated with TSV and relativism would be positively associated with this cultural dimension.

We predicted that idealism and relativism would interact to predict scores on the Inglehart's Survival/ Self-expression values (SSV) dimension. This dimensions "taps a syndrome of trust, tolerance, subjective well-being, political activism, and selfexpression that emerges in postindustrial societies" (Inglehart and Baker, 2000, p. 25). Residents of high scoring nations on the SSV display a degree of 


\section{Ethics Position Theory}

relativism with regards to traditional moral standards, but they are committed to emerging social values that prize equality, environmentalism, and tolerance. These demographics suggest that Western countries, which we expect to be exceptionists, would likely also score higher on SSV dimension.

$H_{3}$ : Idealism and relativism, measured at the international level, will be systematically related to previously documented differences in cultural values and traditions such that: $\left(\mathrm{H} 3_{\mathrm{A}}\right)$ countries where residents express relatively high levels of idealism will have low scores on masculinity (MAS) and traditional/ secular-rational values (TSV); $\left(\mathrm{H}_{3 \mathrm{~B}}\right)$ countries where residents express relatively high levels of relativism will have higher scores on indexes of traditional/secular-rational values (TSV) but lower scores on Individualism (IDV) and Uncertainty Avoidance (UAI); $\left(\mathrm{H}_{3 \mathrm{C}}\right)$ countries where residents are low in idealism and relativism (exceptionists) will have higher scores on Survival/Self-expression values (SSV) index.

\section{Methods}

We tested our hypotheses about cultural differences in ethics ideologies by examining the statistical information provided by researchers in published and unpublished studies that used the EPQ to measure idealism and relativism. The search began online with the Educational Resources Information Center (ERIC), PsycInfo, InfoTrac OneFile, Google Scholar, and Dissertation Abstracts Online. A variety of search terms was used to maximize results including, but not limited to; EPQ, ethics position, Forsyth, idealism, relativism, Machiavellianism, situationist, absolutist, exceptionist, subjectivist, moral and ethics orientation, and moral judgment. We used the Web of Science to locate all papers in that database that referenced Forsyth (1980) or Forsyth (1992) and posted a call for papers - both published and unpublished - on the listserv for the Society for Personality and Social Psychologists (SPSP). We also conducted a manual search of the journal with the most citations for the EPQ, The Journal of Business Ethics, to ensure a more complete examination. The results of these searches revealed clusters of authors, so the next step was to contact these prominent authors in the field and (1) confirm the lists of their publications were complete (2) retrieve unreported statistics needed for the meta-analysis, and (3) request any unpublished studies.

Until recently, the reporting of correlation matrices, means, standard deviations, and reliabilities in many journals was sporadic. This variation in the amount of statistical information presented in studies dating back to 1978 posed a challenge to metaanalysts who rely on these statistics to quantify effects and overall differences. Therefore, it is necessary when conducting a meta-analysis to seek out the authors of publications when a key statistic is missing. This was the case in slightly less than half of the identified articles. A request for more information e-mail and a follow up e-mail two weeks later resulted in the addition of 15 studies that were included in the analysis. When no information was provided, the study could not be included in the meta-analysis.

The literature search identified 220 publications that cited the EPQ in some way. The next step in the systematic review is to decide on inclusion criteria. Beginning with the broadest criterion, an included article must have used the EPQ on a unique sample. Since many of the research questions focus on differences in nationalities and world regions, articles that used a non-English version of the EPQ were included. Although it is not uncommon to drop a small number of items from a scale to increase reliability, an additional inclusion criteria was that the study had to include at least 6 of the 10 items from the original Forsyth (1980) scales.

\section{Regional coding}

For any study, we recorded the year of publication, general citation information, means, standard deviations, and reliabilities of the two scales, as well as sample features and size. Nationality was initially coded as reported in the study, but to make more meaningful conclusions among world regions nationality was also coded into three sociogeographic regions based on geography, culture, colonization influence, and language: eastern (Asia/ Pacific Rim) cultures, western (Europe, Russia, U.S, 
and West Asia) cultures, and Middle Eastern (Middle East, North Africa) cultures. The category of the Western nations was not defined exclusively by geographic region. The impact of Western Europe on other parts of the world, such as Australia and the U.S., makes this category broader than simply the nations on the European continent. For this reason, certain nations are included in that category that are not part of Europe or the former Soviet Republic, but instead are culturally bound through colonization and culture.

The number of studies for any particular country did not allow us to distinguish between regions within a specific country, with one exception: the U.S. Due to the relatively large number of studies conducted using U.S. samples, in some analyses we identified three subcategories: those conducted in the Eastern United States, the Western United States (where the Mississippi River was the dividing line), and those studies that drew participants from across the U.S. We subdivided the U.S. sample, so that cell sizes for that country would not be so disproportionate in comparison to other countries (and thereby increasing heterogeneity of variance), and also because regional variations in such cultural dimensions as individualism/collectivism were identified in prior studies of the U.S. (e.g., Vandello and Cohen, 1999). Table II shows the result of the socio-geographic divisions.

\section{Cultural coding}

When possible, each nation included in the metaanalysis was scored on five cultural dimensions and three cultural values. The five cultural dimensions included power distance, uncertainty avoidance, individualism, masculinity, and long-term orientation (LTO), as defined and indexed by Hofstede (1980; see http://www.geert-hofstede.com/). The primary cultural values, traditional vs. secular rational values (TSV), and survival vs. self-expression values (SSV) were derived from Inglehart and Baker's (2000, p. 30) summary of each nation's location on the dimensions, as indicated by residents' responses to the World Values Survey. We also added a third, more specific, indicator of religious values drawn from the online database of the World Values Survey: the proportion of residents of a particular country to express belief in God (see http://www.worldvaluessurvey.org/). The
World Values Survey database included scores for only a subsample of the nations in our meta-analysis.

Item deletion and scaling

During the coding process, it became apparent that many researchers were factor analyzing the two scales of the EPQ and retaining only the highest loading items. These modified EPQ scales were retained in the analysis, but because significant differences may exist between the full version of the EPQ and the shortened versions of the EPQ, scale length was used as a covariate. Another issue discovered during the data collection phase was differing metrics used on the EPQ. All studies utilized Likert-type scaling, however the metrics ranged from 5-points to 9-points. Since differing metrics can cause differing means as well as alter distributions, scale metric was used as a control variable in the analyses (Schwarz, 1999).

Since different researchers used varying numbers of items and rating-point scales (5, 7, and 9), we converted the reported idealism and relativism information to a common metric. First, when investigators reported totals across the scales rather than means, we converted their results to means by dividing the idealism and relativism scores by the number of items used in the study. Second, in order to convert these means to a common metric the means of the scales were divided by the maximum score possible given the particular scale length used in that particular study. For instance, a mean of 4.5 for idealism, in a study using 9-point scales would be converted to .50 (4.5/9), but a mean of 4.5 for idealism in a study using 7 -point scales would be converted to .64. Therefore, all reported means could range from 0 to 1 , with higher scores indicating greater idealism and relativism.

\section{Meta-analytic data analysis}

Our meta-analysis method was a sample-size weighted ANCOVA with covariates. The samplesize weighting gives greater weights to data from larger samples. The unit of analysis was the country. The dependent variables were the mean of the relativism scale and the mean of idealism scale. 


\section{Ethics Position Theory}

\section{TABLE II}

Number of samples $(k)$ and participants $(N)$ and idealism and relativism means (weighted by no. of each study) and standard deviations for the U.S. and countries in three world regions (total $k=139$, total $N=30,230$ )

\begin{tabular}{|c|c|c|c|c|c|c|c|}
\hline Nation & $k$ & $N$ & Idealism $M$ & Idealism SD & Relativism $M$ & Relativism $S D$ & Region \\
\hline Australia & 8 & 1419 & .727 & 0.040 & .536 & 0.032 & West \\
\hline Austria & 3 & 298 & .757 & 0.055 & .576 & 0.086 & West \\
\hline Belgium & 3 & 1048 & .588 & 0.092 & .539 & 0.094 & West \\
\hline Britain & 3 & 289 & .789 & 0.018 & .690 & 0.035 & West \\
\hline Brunei & 1 & 153 & .821 & - & .709 & - & East \\
\hline Canada & 2 & 331 & .719 & 0.007 & .447 & 0.029 & West \\
\hline China & 5 & 1081 & .716 & 0.040 & .687 & 0.146 & East \\
\hline Egypt & 6 & 1466 & .791 & 0.130 & .550 & 0.044 & Mid East \\
\hline Hong Kong & 6 & 877 & .703 & 0.034 & .669 & 0.012 & East \\
\hline India & 1 & 114 & .778 & - & .682 & - & East \\
\hline Indonesia & 1 & 120 & .752 & - & - & - & East \\
\hline Ireland & 1 & 193 & .734 & - & .687 & - & West \\
\hline Israel & 1 & 284 & .672 & - & .542 & - & West \\
\hline Japan & 2 & 463 & .721 & 0.002 & .686 & 0.061 & East \\
\hline Lebanon & 2 & 592 & .758 & 0.043 & .626 & - & Mid East \\
\hline Malaysia & 3 & 408 & .778 & 0.032 & .625 & 0.051 & East \\
\hline N. Ireland & 1 & 193 & .888 & - & - & - & West \\
\hline New Zealand & 2 & 160 & .682 & - & .589 & 0.014 & West \\
\hline Poland & 1 & 202 & .814 & - & .542 & - & West \\
\hline Russia & 3 & 378 & .728 & 0.017 & .597 & 0.048 & West \\
\hline Saudi Arabia & 1 & 198 & .769 & - & .605 & - & Mid East \\
\hline S. Africa & 1 & 256 & .779 & - & .467 & - & West \\
\hline S. Korea & 2 & 297 & .797 & 0.024 & .604 & 0.013 & East \\
\hline Spain & 1 & 152 & .868 & - & .638 & - & West \\
\hline Thailand & 1 & 98 & .730 & - & .622 & - & East \\
\hline Turkey & 3 & 607 & .811 & 0.040 & .641 & 0.007 & Mid East \\
\hline UAE & 1 & 208 & .759 & - & .618 & - & Mid East \\
\hline Ukraine & 1 & 30 & .788 & - & .609 & - & West \\
\hline US East & 27 & 6699 & .712 & 0.098 & .577 & 0.077 & West \\
\hline US mixed & 32 & 8235 & .718 & 0.049 & .547 & 0.062 & West \\
\hline US West & 14 & 3197 & .741 & 0.050 & .626 & 0.044 & West \\
\hline Grand Mean & & & .728 & 0.079 & .586 & 0.076 & \\
\hline
\end{tabular}

\section{Results}

Our analyses are based on 139 independent samples from 81 studies conducted with residents of 29 nations totaling 30,230 participants. We use these data to first explore measures of central tendency and dispersion for the idealism and relativism scales, their interdependence, and also several psychometric issues pertaining to scale and response-scale length. We then examined variations in relativism and idealism across the 29 nations in the sample to determine if regional differences exist, and if these differences are related to previously documented differences between nations in terms of values, practices, and relationships.

\section{Idealism and relativism: descriptive and psychometric} statistics

Table II presents the descriptive statistics for the studies used in the meta-analysis, including the number of samples $(k)$, sample size $(N)$, means, standard deviations, and socio-geographic region for 
each nation. So that studies based on a small number of subjects would not contribute as much to the computations as studies with larger numbers of subjects, we computed the means shown in Table II by weighting the converted mean reported in the publication by sample size when multiple studies were conducted within a single country.

As Table II indicates, the means for idealism and relativism were .728 and .586 , respectively. These means, if converted to the original EPQ metric (scores ranging from 10 to 90, using a 9-point scale for 10 items per scale), would correspond to 65.52 for idealism and 52.74 for relativism. The means, by nation, ranged from a low of .588 to a high of .888 for idealism and .447 to .709 for relativism. These ranges, if converted to the original EPQ metric, would correspond to 52.9 to 79.9 for idealism and 40.2 to 63.8 for relativism. Although not shown in Table II, the medians for idealism and relativism were .734 and .606 , respectively.

We calculated the correlation between idealism and relativism using the independent samples as the unit of analysis and again using nations as the level of analysis. These correlations were positive, but not significant, in both cases; $r(128)=.11$, and $r(27)=.27$, respectively. This correlation, if calculated based on the means weighted by the sample size, was .26 and was significant only if the sample size was based on the entire number of participants with valid data for both idealism and relativism ( $n=28,540$ since all studies did not include both scales of the EPQ).

We also examined the impact of two measurement variables - scale length and response-scale length - on idealism and relativism in two 5 (number of items: $6,7,8,9$, or 10) $\times 3$ (response scale length: 5,7 , or 9 choices) sample-sizeweighted least squares ANOVAs (one for idealism and one for relativism). The significant main effect of number of items for idealism, $\mathrm{F}(4,124)=3.37$, $p<.012$, indicated that the more items used to assess idealism, the lower the idealism scores. The adjusted means, from 6 to 10 item scales, were .794, $.741, .826, .728$, and .719 . No other effects reached significance for idealism, so we controlled for number-of-items in subsequent analyses of idealism. Since no effects were significant in the analysis of relativism, measurement variables were ignored in subsequent analyses of this variable.

\section{Cross-cultural differences in idealism and relativism}

The 27 nations for which data on both idealism and relativism are available are presented in Figure 1. As that figure indicates, Canada and South Africa were the least relativistic countries, in comparison to the highly relativistic Brunei and Britain. Belgium and Austria had the lowest idealism scores, and Spain, Brunei, Poland, and Turkey had the highest idealism scores. Northern Ireland is not shown in Figure 1 since the one study conducted in that country did not report a relativism score; however, the .888 idealism for that country makes it the most idealistic country in the database.

\section{Regional differences in idealism}

We tested for regional differences in idealism in a one-way sample-size-weighted least squares ANCOVA using region (U.S., Eastern, Western, Middle Eastern) as the predictor variable, and the number of items used in the scale as a covariate (given its significant relationship to idealism, noted above). The significant effect of region, as summarized in Table III, only partially supported $\mathrm{H}_{1 \mathrm{~A}}$. Western nations were, as anticipated, less idealistic, but only relative to the more idealistic Middle East nations. The Eastern nations fell intermediate to and not different from either the Middle East nations or the Western nations.

\section{Regional differences in relativism}

A one-way sample-size-weighted least squares ANOVA using region (U.S., Eastern, Western, Middle East) as the predictor variable yielded a significant effect of region, which supported $\mathrm{H}_{1 \mathrm{~B}}$. As Table III indicates, respondents living in the Eastern regions of the world expressed higher levels of relativism than Westerners, with Middle Easterners falling intermediate to and not different from either group.

\section{Cross-cultural differences in ethics positions}

Figure 1 also indicates each nation's classification into an ethics position: absolutism, situationism, exceptionism, and subjectivism. Consistent with most prior studies, by separating the nations at the median for idealism (.734) and relativism (.606) we 


\section{Ethics Position Theory}

TABLE III

Idealism and relativism means in four world regions

\begin{tabular}{|c|c|c|c|c|c|c|}
\hline \multirow[t]{2}{*}{ Item } & \multicolumn{4}{|c|}{ Means } & \multirow[t]{2}{*}{ Region F-ratio } & \multirow[t]{2}{*}{$d f \mathrm{~s}$} \\
\hline & US & Eastern & Western & Middle East & & \\
\hline Idealism & $.720^{\mathrm{a}}$ & $.735^{\mathrm{ab}}$ & $.719^{\mathrm{a}}$ & $.775^{\mathrm{b}}$ & $2.82^{\star}$ & 3,133 \\
\hline Relativism & $.568^{\mathrm{a}}$ & $.642^{\mathrm{b}}$ & $.557^{\mathrm{a}}$ & $.587^{\mathrm{ab}}$ & $4.54 \star \star$ & 3, 127 \\
\hline
\end{tabular}

Note: For any dependent variable, means that do not share a common single letter subscript are different at the $p<.05$ by Duncan's New Multiple Range Test.

$\star_{p}<.05$.

$\star \star p<.01$.

could classify the majority of the 29 nations (and 3 U.S. regions) into one of the categories defined by Ethics Positions Theory. Five nations were classified as absolutist in their ethics position: South Africa, Poland, and Egypt, and to a lesser degree Saudi Arabia and Korea, endorsed an absolutist moral philosophy. Eight countries (Spain, Brunei, Turkey, Britain, India, Malaysia, Lebanon, and the UAE) were situationists, as well as the western segment of the U.S. Hong Kong, Japan, Thailand, and China were the four-subjectivist nations. Eight countries (34.8\%) were classified as exceptionists: Belgium, Austria, Israel, New Zealand, the U.S. (east and mixed), Australia, Canada, and Russia. Thus, exceptionism and situationism were the most common ethics positions at the national level, displayed

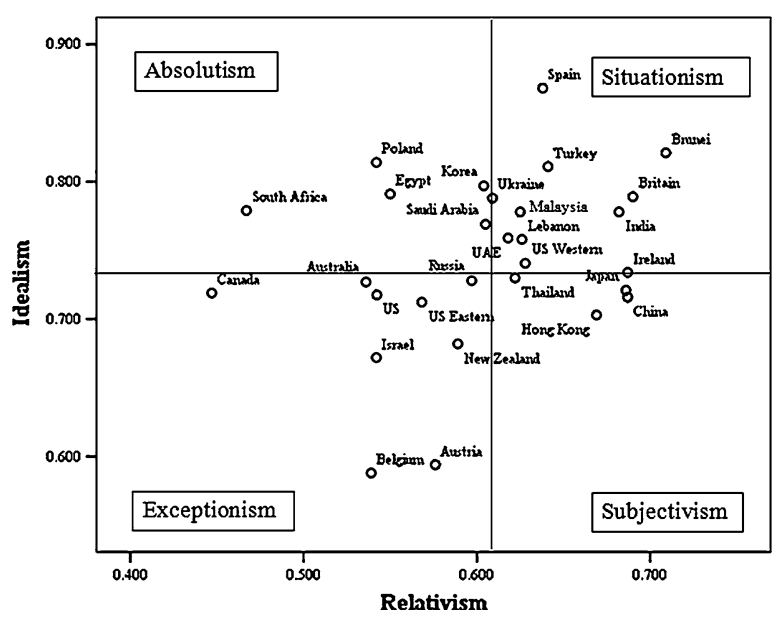

Figure 1. Locations of 29 nations on the two dimensions of idealism and relativism. by two-thirds of the countries in the survey, and subjectivism and absolutism were nearly equally endorsed by the remaining nations. (Ukraine's score for relativism and Ireland's score for idealism fell so near the median that they could not be classified as either high or low.)

A 4 (region) $\times 4$ (ethics position) frequency analysis, $\chi^{2}(9, n=27)=21.68, p<.01$, indicated that residents of different nations in different regions of the world tended to endorse different ethics positions. Consistent with $\mathrm{H}_{2 \mathrm{~A}}$ and the regional differences reported above for the continuous idealism and relativism variables, a majority of the Western countries (63.6\%) shared exceptionism as their national moral philosophy. None of the Eastern nations were classified as exceptionists: instead, and as is generally consistent with $\mathrm{H}_{2 \mathrm{~B}}$, most $(87.5 \%)$ were evenly divided between situationism and subjectivism, the highly relativistic positions. The Middle Eastern countries tended to be idealistic ones as $\mathrm{H}_{2 \mathrm{C}}$ predicted, but they were divided between absolutism (Egypt, Saudi Arabia) and situationism (Lebanon, Turkey, United Arabs Emirate).

\section{Idealism, relativism, and cultural values}

We hypothesized that measures of idealism and relativism, aggregated at the national level, would be related to previously documented differences in cultural values and traditions. We tested this hypothesis in a series of 2 (Idealism: high vs. low) 2 (Relativism: high vs. low) sample-size-weighted least squares ANOVAs. The results of these analyses are summarized in Table IV and in Figure 2. 
Donelson R. Forsyth et al.

TABLE IV

ANOVA results for test main effects of idealism (I), relativism $(R)$, and their interaction $(I \star R)$ on indices of world values

\begin{tabular}{lccccc}
\hline Item & \multicolumn{3}{c}{ Anova F-ratios } & \multirow{2}{*}{ Error MS } & $d f \mathrm{~s}$ \\
\cline { 2 - 4 } & $\mathrm{I}$ & $\mathrm{R}$ & $\mathrm{I} \star \mathrm{R}$ & & \\
\hline Traditional/Secular-rational values (TSV) & $14.42^{\star \star \star}$ & $7.17 \star \star$ & $3.14^{\dagger}$ & 1.63 & 1,21 \\
Belief in God & $20.11^{\star \star \star}$ & $12.96^{\star \star}$ & 1.53 & 180.6 & 1,11 \\
Survival/Self-expression values (SSV) & $4.33^{\star}$ & 3.64 & $8.82^{\star \star}$ & 2.19 & 1,21 \\
Power distance index (PDI) & $3.93^{\dagger}$ & 2.85 & $3.41^{\dagger}$ & 3959.1 & 1,21 \\
Individualism (IDV) & 2.89 & $10.63 \star \star$ & $16.55^{\star \star \star}$ & 1153.5 & 1,21 \\
Masculinity (MAS) & $4.79 \star$ & 0.13 & 0.07 & 384.7 & 1,21 \\
Uncertainty avoidance (UAI) & 2.15 & $5.15 \star$ & 0.18 & 1133.7 & 1,21 \\
Long-term orientation (LTO) & 2.86 & 1.01 & $8.40 \star \star$ & 1192.8 & 1,8 \\
\hline
\end{tabular}

${ }^{\dagger} p<.10$.

$\star_{p}<.05$.

$\star \star p<.01$.

$\star \star \star p<.001$.

Idealism and cultural values

$\mathrm{H}_{3 \mathrm{~A}}$ predicted that countries where residents express relatively high levels of idealism would score lower on the Ingelhart (1997) index of traditional/secularrational values (TSV) and Hofstede's (1980) index of masculinity (MAS). This hypothesis was supported by significant main effects of idealism on both these indices. As the means shown in Figure 2(a, f) indicates, the TSV and MAS scores for idealistic countries - the absolutists and situationists - were lower than those for less idealistic countries - the exceptionists and subjectivists; the Ms were -.76 and .24 for TSV and 50.73 and 58.42 for MAS.

Figure 2 also presents findings pertaining to one specific item that contributes to the traditional/ secular-rational values (TSV) scale: Percentage of country residents who express a belief in God. The significant main effect of idealism on this item, as Figure 2(b) indicates, confirms that individuals in idealistic countries were more likely to report a belief in God than those in less idealistic countries; the Ms were $92.43 \%$ and $75.89 \%$.

\section{Relativism and cultural values}

$\mathrm{H}_{3 \text { в }}$ predicted that countries where residents express relatively high levels of relativism would score higher on the Ingelhart (1997) traditional/secularrational values (TSV) scale but lower scores on Hofstede's (1980) index of Individualism and
Uncertainty Avoidance. This prediction was supported by the main effects of relativism for these variables reported in Table IV and shown in Figure 2(a, e, g). The relativism main effect for TSV, IDV, and UAI indicate that high relativist nations, compared to low relativist nations, were more traditional (TSV Ms $=.07$ and -.77 ) and lower in individualism (IDV Ms $=35.70$ and 62.79, respectively) and uncertainty avoidance (UAI Ms $=48.63$ and 67.32, respectively). However, as noted below, the findings reported in Table IV and Figure 2(c, e) add a qualification to the overall confirmation of $\mathrm{H}_{3 \mathrm{~B}}$.

Relativism, idealism, and cultural values

As Figure 2(c) clearly indicates, most of the nations in our sample had relatively moderate scores on the SSV index; only the exceptionist nations (low relativists and low idealists), as $\mathrm{H}_{3 \mathrm{C}}$ hypothesized, strongly endorsed values that emphasized self-expression, trust, tolerance, and personal happiness.

These results, along with other findings presented in Table IV and in Figure 2, suggest that the strength of the relationship between idealism and a number of cultural values was moderated, to some extent, by relativism. When low idealism was combined with low relativism, yielding an exceptionist moral position, individuals were more likely to endorse self-expression values rather than survival values and individualism rather than collectivism. 
Ethics Position Theory
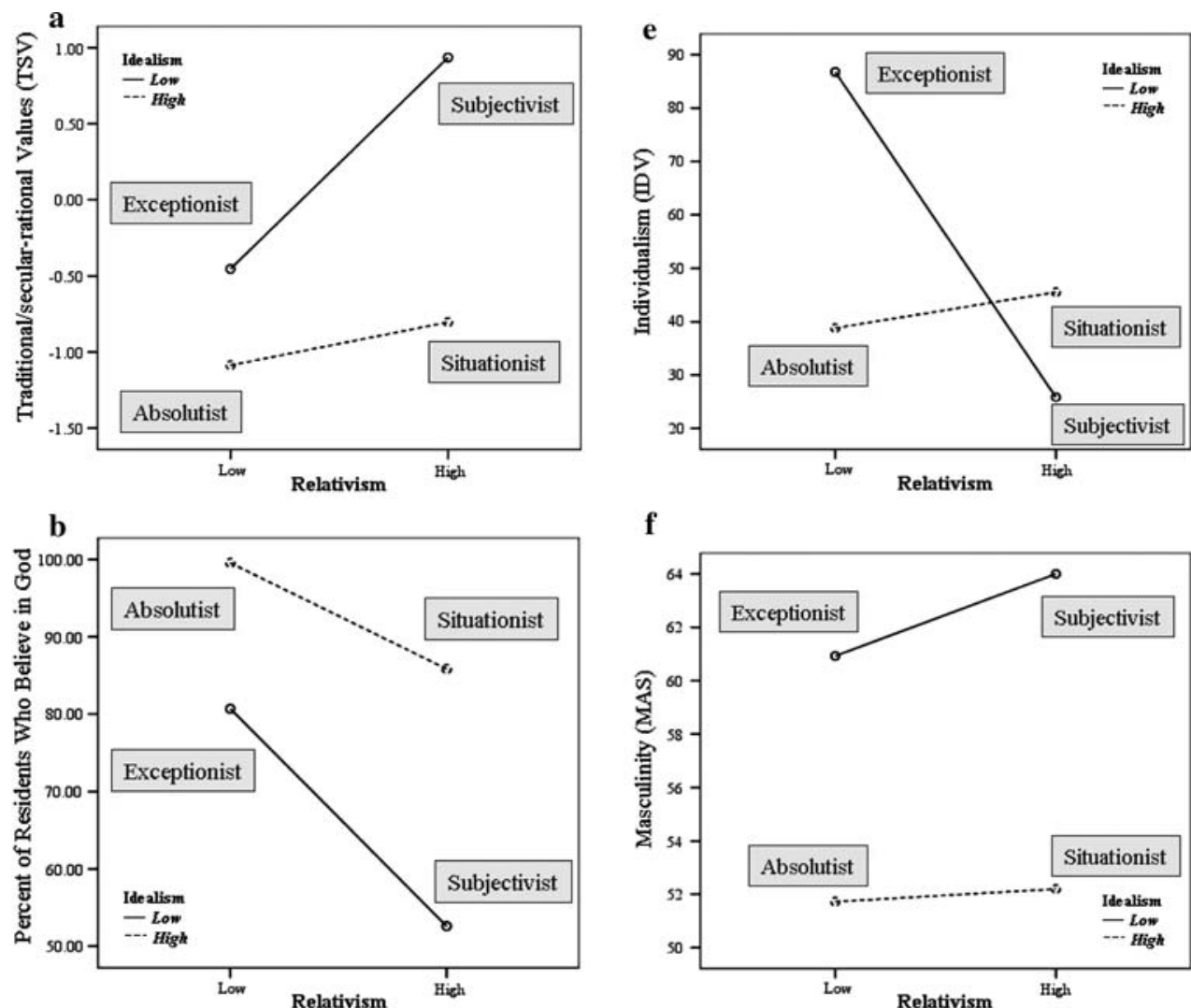

f
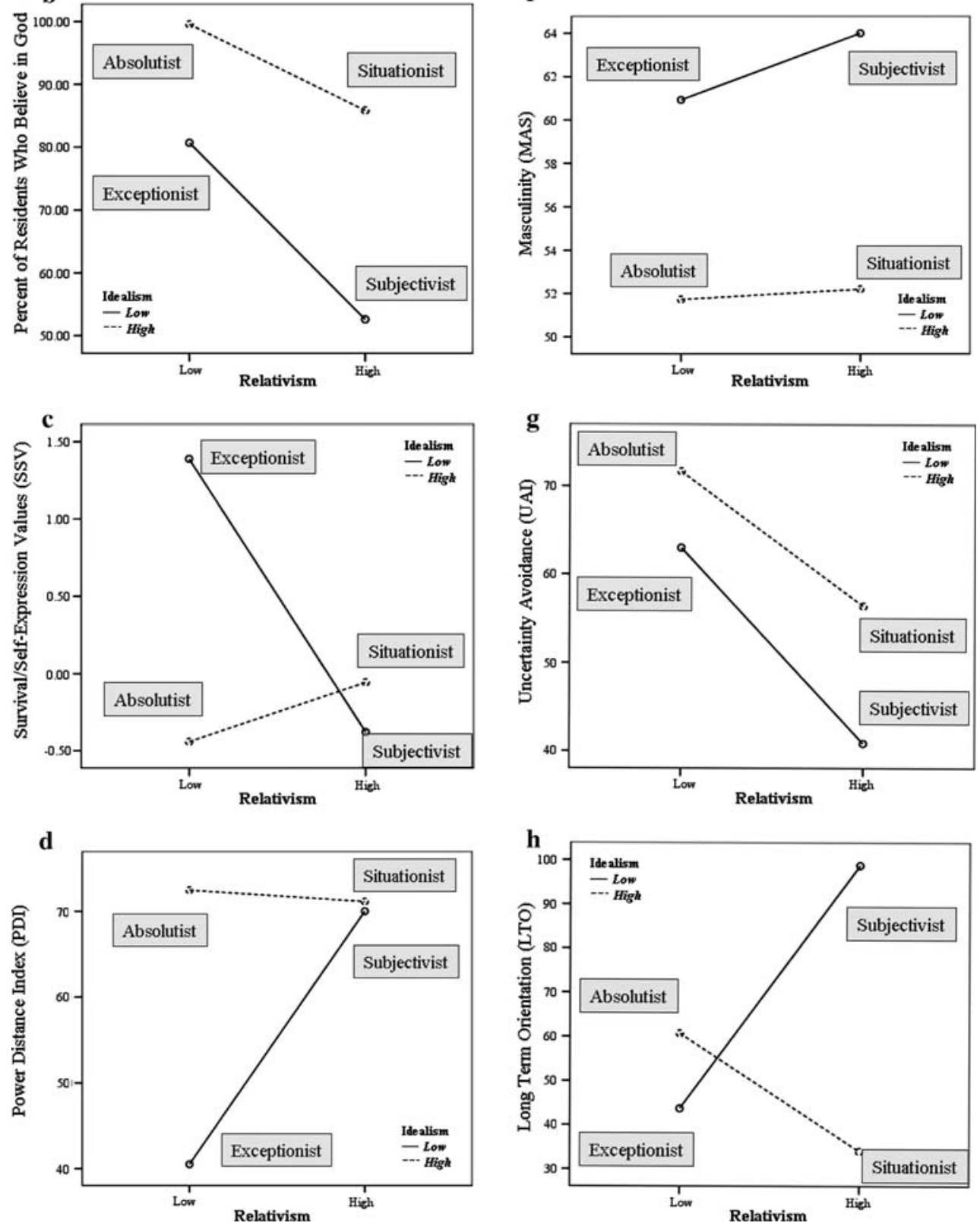

Figure 2. Mean cultural values and dimensions for exceptionist, subjectivist, absolutist, and situationist nations. 
They were also somewhat more likely to score lower on the power distance index (PDI). When, in contrast, low idealism was combined with high relativism, yielding a subjectivist moral position, individuals were more likely to endorse secularrational values and a LTO. These findings suggest that, in some cases, cultural values are predicted by a combination of idealism and relativism, rather than by either idealism or relativism alone.

\section{Discussion}

Relying on meta-analytic methods to organize prior studies that used the EPQ to measure idealism and relativism in countries around the world, we found support for the three basic hypotheses: (a) mean levels of idealism and relativism vary across regions of the world in predictable ways; (b) countries can be classified on the basis of residents' EPQ scores into one of four ethics positions: exceptionists (Westerners), subjectivists and situationists (Easterners), and absolutists and situationists (Middle Easterners); and (c) variations in idealism and relativism are consistent with prior studies of cultural differences (e.g., Hofstede, 1980; Ingelhart and Baker, 2000).

\section{Idealism, relativism, and culture}

Where are idealism and relativism highest and where are they lowest? Idealism, as conceptualized within EPT, was reduced in many of the more commercially focused and entrepreneurial countries in the Eastern and Western world, such as the U.S., Hong Kong, China, and Australia. Idealism waxed, in contrast, in a number of European, Eastern, and Middle East countries that were characterized by lower scores on the Hofstede (1980) femininity-masculinity dimension. Relativism, in contrast, peaked in the collectivistic nations of the world and where people expressed less traditional values and orientations. The Asian countries of the East consistently scored higher in relativism, although they were joined by some unexpected company; England and Ireland, for example. Less relativistic countries were similar in that residents tended to express relatively orthodox, traditional values about religion and they were more oriented toward UAI and more accepting of power distances in social relationships.

As a result of these tendencies, Western countries such as the U.S., Belgium, Austria, and Canada, could be classified as exceptionistic in their nationallevel ethics position. Eastern countries, in contrast, tended to fall into the subjectivist category (e.g., Hong Kong, China, Japan) or situationism (Malaysia, India, and possibly Korea). Absolutists' locales varied, and included several Middle Eastern countries (Egypt, Saudi Arabia), Poland, and South Africa.

Interestingly, these nation-level variations in ethics positions were associated with differences along a number of key cultural dimensions. Exceptionist nations (low idealism, low relativism, such as the U.S.) differed from all other ethics positions in terms of their self-expression values, their rejection of power-distance relationships, their emphasis on individuality over collectivism, and their masculine orientation. Subjectivist nations, in contrast (low idealism, high relativism, such as Hong Kong), were different from other nations in their rejection of traditional values, low levels of UAI, pronounced LTO, and low proportion of residents who reported believing in God.

These findings clarify, to a degree, the conceptual meaning of the dimensions of the EPQ, but they also provide additional details regarding the nature of cross-cultural differences in individualism/collectivism. Forsyth (1980, p. 178) labeled individuals who agreed with such items as "One should never psychologically or physically harm another person," "If an action could harm an innocent other, then it should not be done," and "Deciding whether or not to perform an act by balancing the positive consequences of the act against the negative consequences of the act is immoral" idealists, but the current findings suggest that they tend to be more traditional, conservative, and religious as well. Similarly, Forsyth (1980, p. 178) labeled those who agreed with such statements as "Different types of moralities cannot be compared as to rightness," "What is ethical varies from one situation and society to another," and "Whether a lie is judged to be moral or immoral depends upon the circumstances surrounding the action" relativists, but the current results suggest that they are also collectivistic, 


\section{Ethics Position Theory}

logical/rational, less uncertainty-averse, and possibility less traditionally religious.

One of the most surprising aspects of these results was the relatively complex picture it provides of the concept of individualism/collectivism. We predicted, on the basis of the reasonable expectation that individuals in Eastern countries would be both relativistic and collectivistic, an association between these two dimensions (Diener et al., 2005). However, theoretically, it could be individualists, given their stress on independence over interdependence, who would also be likely to resist basing their moral judgments on universal principles that apply across people. What we found, however, was that individualism/collectivism is predicted by the interaction of both idealism and relativism, for the exceptionists were individualistic whereas as the equally nonidealistic subjectivists were collectivistic. These findings serve as a warning to consider, when possible, not only the bivariate relationships between idealism and relativism and other variables, but also the joint effects of idealism and relativism. Such relationships can be detected either by classifying participants into ethics positions or through the use of moderated multiple-regression procedures.

\section{Limitations and concerns}

Limitations in the methods we used in this study should not be disregarded. We grouped entire nations into three broad categories, and so were not sensitive to the many unique aspects of the religions and philosophies of the nations in these geopolitical clusters. As a meta-analysis, the validity of the conclusions depends on the quality of the procedures used by hundreds of researchers working in countries around the world. Researchers who used unusual sampling methods, administered the EPQ incorrectly, translated the EPQ inaccurately, or misreported their findings influenced the conclusions we drew from their work. Some studies, too, had to be eliminated from our analysis simply because the investigators did not report basic statistics about the scales, or they decided to administer only one scale rather than both scales.

The results must also be interpreted with caution given the psychometric weaknesses of the EPQ, which was the scale used to assess both idealism and relativism in the studies we reviewed. In some cases researchers reported that could replicate the original factor structure of the EPQ, particularly for U.S., English-speaking participants (e.g., Forsyth et al., 1988; MacKewn and Van Vuren, 2007). Many researchers, however, find that they must modify the items in the original scale to improve the measure's psychometric fitness. When, for example, Davis et al. (2001) conducted a confirmatory factor analysis of the EPQ they discovered that the relativism scale was too heterogeneous to be summed into a single scale score. Their findings suggested splitting the two items pertaining to lying out from the other items (and also deleting an item that contributed little to the overall internal consistency of the relativism scale). Similarly Cui et al. (2005) reported that the conceptual meaning of the two scales held up across the five societies they studied (Austria, Britain, Brunei, Hong Kong, and USA), but that no one basic factor pattern generalized across all cultures.

These findings suggest that the EPQ should be used with caution as a measure of moral thought, particularly when it is translated and administered to individuals from non-U.S. cultures. Not only may the meaning of the items vary from one language to another, but also the very meanings of the dimensions themselves may shift from one culture to the next. Relativism, for example, may mean something different to someone raised in the U.S. in comparison to Eastern or Middle Eastern relativism. Redfern (2004, pp. 206-207), suggesting just this possibility, notes "the Chinese 'Relativist' strays from the Western 'Relativist' in that decisions are made through a largely irrational and non-material approach which relies more on the intuition of the individual in the pursuit of higher ideals or 'virtues', of which guide decision making in each situation." Indeed, as cross-cultural psychologist Bond (2000) noted, to assume that a measure that was developed with U.S. citizens can be used without reservation with those with widely differing cultural backgrounds is imperialistic, particularly when researchers focus so exclusively on idealism and relativism that they ignore other, indigenous, aspects of morality that are unique to a given cultural context.

These limitations lead us to this methodological plea: When using the EPQ, investigators should publish the basic statistics for the two scales so that 
the findings can be used in subsequent metaanalyses. Also, it would be helpful if reports included the means of the total, 10-item scales as well as the means for reduced scales even if such psychometric trimming proves to be necessary. In a number of cases researchers sought to increase the internal consistency of the EPQ scales by eliminating items that did not contribute to the psychometric consistency of the scales, but because of this tweaking of the scales our findings are not based on a single set of unified measures of idealism and relativism.

Another methodological limitation can be traced to the small number of samples for some of the regions we investigated. As with all empirical efforts, we would be more confident that the means in Table II reflect the true value of idealism and relativism in the population of a specific country if the reported statistics are based on larger samples and multiple studies. In cases such as Israel, Saudi Arabia, and Indonesia, we could locate only one study that provided the necessary information to use in the meta-analysis, and as a result the nuances of that study's sample and procedures may have determined the location of that country in Figure 2. As studies are added to the database, the location of each country may shift accordingly, and in proportion to the size of the current database. With so many subjects for such countries as the U.S., Australia, and Hong Kong their location should not change with each new study. However, other countries whose locations are based on fewer data points may move their location.

Still, 30,000 subjects is a reassuringly substantial number of participants, as are the theoretically and empirical relationships that emerged in this study. Despite the lack of consistency in the procedures of the studies we examined - which undoubtedly resulted in substantial noise in the aggregated data set - predictions derived from the EPT and from prior studies of cross-cultural differences in values were largely confirmed.

\section{Implications}

It is often said that leadership that is not ethical is not good leadership, and that the ethical company will in time outperform one that takes moral shortcuts. Such sage pronouncements, however, overlook the cultural specificity of morality, for what is considered ethical in one country may invoke moral outrage in another. Progressive business professionals may wish to "do the right thing," but this guiding principle may be of little help, when they find themselves in cultures where their personal conceptions of morality are at odds with the moral actions and judgments of those around them.

As globalization continues apace people are more frequently living and working in cultural contexts whose moral practices and pronouncements seem, at least initially, incoherent and arbitrary. In one country people may seem to not only tolerate, but also actively encourage, bribery and nepotism. Yet, saying something critical about a respected member of the community or excusing oneself from a shared meal may in this same country be roundly condemned. In another culture people consider bribery to be morally indefensible, but they show little loyalty to their employers and reward themselves before they make sure others receive their due share. Contrast that culture with one where people negotiate every business transaction with grace and politeness, yet when they make decisions they seem to ignore the negative impact that their choices will have on people who are outside of their social circle.

Ethics position theory, and the findings reported here pertaining to cultural variations in idealism and relativism, offer a way of conceptualizing and coping with living in a moral world that seems different from the one where one was raised. EPT assumes that that the specific moral expectations and practices of a particular cultures are not wholly arbitrary or idiosyncratic, but instead reflect underlying differences in idealism and relativism. Just as personality researchers find that the bewildering variety of personality traits can be distilled down to small number of key differences such as introversion/extraversion and neuroticism, so the current findings suggest that the many variations in how cultures approach questions of moral goodness depend, in part, on each cultures' orientation towards harm and conformity to the normative standards of that society. In a more idealistic culture, the populace may find the aggressive, materialistic, high achievement motivation, and masculinity of a traditional business orientation to be morally offensive, for such an orientation is antithetical to the person-centered, humble, nurturing, and interpersonally sensitive 


\section{Ethics Position Theory}

orientation of high idealism. In contrast, when the culture stresses traditional religious values, conformity to codes of right and wrong, and moral rights, then its members are likely to condemn a relativistic orientation to morality that eschews absolutism in favor of a contextual weighting of the demands of social duty and responsibility in the given context. One may understand the language and customs of those one works with, sells to, and buys from, but if one enters into a social exchange without understanding how one's partners in the process think about issues of morality, then the experience will likely end badly.

\section{References}

\section{* Indicates study was used in the meta-analytic review}

Abeng, T.: 1997, 'Business Ethics in Islamic Context: Perspectives of a Muslim Business Leader', Business Ethics Quarterly 7, 47-54.

Abratt, R., D. Nel and N. S. Higgs: 1992, 'An Examination of the Ethical Beliefs of Managers Using Selected Scenarios in a Cross-Cultural Environment', Journal of Business Ethics 11, 29-34.

Ahmed, M. M., K. Y. Chung and J. W. Eischenseher: 2003, 'Business Students' Perception of Ethics and Moral Judgment: A Cross-Cultural Study', Journal of Business Ethics 43, 89-102.

*Al-Khatib, J. A., K. Dobie and S. J. Vitell: 1995, 'Consumer Ethics in Developing Countries: An Empirical Investigation', Journal of European Marketing 4, 87-109.

*Al-Khatib, J. A., C. J. Robertson and D. Lascu: 2004, 'Post-Communist Consumer Ethics: The Case of Romania', Journal of Business Ethics 54, 81-96.

*Al-Khatib, J. A., A. D. Stanton and M. Y. A. Rawwas: 2005, 'Ethical Segmentation of Consumers in Developing Countries: A Comparative Analysis', International Marketing Review 22, 225-246.

*Auger, P. and T. M. Devinney: 2005, Do What Consumers Say Matter? Unpublished manuscript. Melbourne Business School, Victoria, Australia.

*Axinn, C., M. Blair and A. Thach: 2004, 'Comparing Ethical Ideologies Across Cultures', Journal of Business Ethics 54, 103-120.

^Banas, J. T. and J. M. Parks: 2002, 'Lambs Among Lions? The Impact of Ethical Ideology on Negotiation
Behaviors and Outcomes', International Negotiation 7, 235-260.

*Barnett, T., K. Bass and G. Brown: 1994, 'Ethical Ideology and Ethical Judgment Regarding Ethical Issues in Business', Journal of Business Ethics 13, 469-480.

*Barnett, T., K. Bass and G. Brown: 1996, 'Religiosity, Ethical Ideology, and Intentions to Report a Peer's Wrongdoing', Journal of Business Ethics 15, 1161-1174.

^Barnett, T., K. Bass, G. Brown and F. J. Hebert: 1998, 'Ethical Ideology and the Ethical Judgments of Marketing Professionals', Journal of Business Ethics 17, 715-723.

Bellah, R. N., R. Madsen, W. M. Sullivan, A. Swidler and S. M. Tipton: 1985, Habits of the Heart: Individualism and Commitment in American Life (University of California Press, Berkeley).

*Bhal, K. T. and N. Debnath: 2006, 'Conceptualizing and Measuring Gunas: Predictors of Workplace Ethics of Indian Professionals', International Journal of Cross Cultural Management 6, 169-188.

Bond, M. H.: 2000, 'Localizing Imperial Outreach: The Big Five and More in Chinese Culture', American Behavioral Scientist 44, 63-72.

^Bowes-Sperry, L. and G. N. Powell: 1999, 'Observers' Reactions to Social-Sexual Behavior at Work: An Ethical Decision Making Perspective', Journal of Management 25, 779-802.

Brown, L. M., C. Gilligan and M. B. Tappan: 1995, 'Listening to Different Voices', in W. M. Kurtines and J. L. Gewirtz (eds.), Moral Development: An Introduction (Allyn \& Bacon, Boston), pp. 311-333.

^Byers, B. and W. G. Powers: 1997, 'Criminal Justice and Ethical Ideology: An Exploration of a LoyaltyTruthfulness Dilemma', Journal of Criminal Justice 25, 527-540.

${ }^{\star}$ Caswell, S. V.: 2003, Individual Moral Philosophies and Ethical Decision Making of Undergraduate Athletic Training Education Students and Instructors. Unpublished Doctoral Dissertation, Ohio University, Athens, $\mathrm{OH}$.

${ }^{\star}$ Caswell, S. V., T. E. Gould and A. M. Allen: 2005, 'Is Competition Level Related to Athletic Trainers' Ethical Ideologies and Ethical Decision-Making in Collegiate Settings?', Journal of Athletic Training 40, 63.

${ }^{\star}$ Catlin, D. W. and J. R. Maupin: 2002, 'Ethical Orientations of State Police Recruits And One-Year Experienced Officers', Journal of Criminal Justice 30, 491-498.

Chan, A., S. Wong and P. Leung: 1998, 'Ethical Beliefs of Chinese Consumers in Hong Kong', Journal of Business Ethics 17, 1163-1170.

${ }^{\star}$ Chan, S. Y. S. and P. Leung: 2006, 'The Effects of Accounting Students' Ethical Reasoning and Personal 
Donelson R. Forsyth et al.

Factors on Their Ethical Sensitivity', Managerial Auditing Journal 21, 436-457.

${ }^{\star}$ Chiu, R. K. and C. B. Erdener: 2003, 'The Ethics of Peer Reporting in Chinese Societies: Evidence from Hong Kong and Shanghai', International Journal of Human Resource Management 14, 335-353.

${ }^{\star}$ Chui, R. K. and A. F. Stembridge: 2001, 'How Managers Judge Whether or Not They Want to Report a Peer's Unethical Behavior', InFo 4, 5-16.

^Chonko, L. B., T. R. Wotruba and T. W. Loe: 2002, 'Direct Selling Ethics at the Top: An Industry Audit and Status Report', Journal of Personal Selling \& Sales Management 22, 87-95.

*Clikeman, P. M., B. N. Schwartz and M. H. Lathan: 2001, 'The Effect of the 150-Hour Requirement on New Accountants' Professional Commitment, Ethical Orientation, and Professionalism', Critical Perspectives on Accounting 12, 627-645.

${ }^{\star}$ Comunale, C. L., T. R. Sexton and S. C. Gara: 2006, 'Professional Ethical Crises', Managerial Auditing Journal 21, 636-656.

${ }^{\star}$ Cui, C. C., V. Mitchell, B. B. Schlegelmilch and B. Cornwell: 2005, 'Measuring Consumers' Ethical Position in Austria, Britain, Brunei, Hong Kong, and USA', Journal of Business Ethics 62, 57-72.

Dahlsgaard, K., C. Peterson and M. E. P. Seligman: 2005, 'Shared Virtue: The Convergence of Valued Human Strengths Across Culture and History', Review of General Psychology 9, 203-213.

Davis, M. A., M. G. Andersen and M. B. Curtis: 2001, 'Measuring Ethical Ideology in Business Ethics: A Critical Analysis of the Ethics Position Questionnaire', Journal of Business Ethics 32, 35-53.

Davis, M. A., N. B. Johnson and D. G. Ohmer: 1998, 'Issue-Contingent Effects on Ethical Decision Making: A Cross-Cultural Comparison', Journal of Business Ethics 17, 373-389.

^Deering, T. E.: 1998, 'The Ethical Perspective of British and American Pre-Service Teachers', Educational Research 40, 353-358.

Diener, E., S. Oishi and U. Schimmack: 2005, 'Individualism: A Valid and Important Dimension of Cultural Differences Between Nations', Personality and Social Psychology Review 9, 17-31.

*Douglas, P. C., R. A. Davidson and B. N. Schwartz: 2001, 'The Effect of Organizational Culture and Ethical Orientation on Accountants' Ethical Judgments', Journal of Business Ethics 34, 101-121.

^Douglas, P. C., H. Hassab Elnaby, C. S. Norman and B. Wier: 2007, 'An Investigation of Ethical Position and Budgeting Systems: Egyptian Managers in US and Egyptian Firms', Journal of International Accounting Auditing \& Taxation 16, 90-109.
Douglas, P. C. and B. Wier: 2005, 'Cultural and Ethical Effects in Budgeting Systems: A Comparison of U.S. and Chinese Managers', Journal of Business Ethics 60, 159-174.

*Eastman, J. K. K. L. Eastman and M. A. Tolson: 2001, 'The Relationship Between Ethical Ideology and Ethical Behavior Intentions: An Exploratory Look at Physicians' Responses to Managed Care Dilemmas', Journal of Business Ethics 31, 209-224.

Erffmeyer, R. C., B. D. Keillor and D. T. LeClair: 1999, 'An Empirical Investigation of Japanese Consumer Ethics', Journal of Business Ethics 18, 35-50.

^Fisher, M., B. Small, H. Roth, M. Mallon and B. Jerebine: 2005, 'What Do Individuals in Different Science Groups Within a Life Sciences Organization Think About Genetic Modification?', Public Understanding of Science 14, 317-326.

*Forsyth, D. R.: 1980, 'A Taxonomy of Ethical Ideologies', Journal of Personality and Social Psychology 39, 175-184.

Forsyth, D. R.: 1985, 'Individual Differences in Information Integration During Moral Judgment', Journal of Personality and Social Psychology 49, 264-272.

Forsyth, D. R.: 1992, 'Judging the Morality of Business Practices: The Influence of Personal Moral Philosophies', Journal of Business Ethics 11, 461-470.

Forsyth, D. R.: 1994, 'Honorable Intentions Versus Praiseworthy Accomplishments: The Impact of Motives and Outcomes on the Moral Self', Current Psychology: Developmental, Learning, Personality, Social 12, 296-311.

Forsyth, D. R. and J. L. Nye: 1990, 'Personal Moral Philosophy and Moral Choice', Journal of Research in Personality 24, 398-414.

Forsyth, D. R., J. L. Nye and K. Kelley: 1988, 'Idealism, Relativism, and the Ethic of Caring', Journal of Psychology 122, 243-248.

*Galvin, S. L. and H. A. Herzog Jr.: 1998, 'Attitudes and Dispositional Optimism of Animal Rights Demonstrators', Society \& Animals 6, 1-11.

*Giacalone, R. A., S. Fricker and J. W. Beard: 1995, 'The Impact of Ethical Ideology on Modifiers of Ethical Decisions and Suggested Punishment for Ethical Infractions', Journal of Business Ethics 14, 497-510.

${ }^{\star}$ Greenfield, A. C., C. S. Norman and B. Wier: 2006, The Effect of Ethical Orientation and Professional Commitment on Earnings Management Behavior. Unpublished Manuscript, Virginia Commonwealth University, Richmond, VA.

Ha, S. and S. J. Lennon: 2006, 'Purchase Intent for Fashion Counterfeit Products: Ethical Ideologies, Ethical Judgments, and Perceived Risks', International Textile and Apparel Association 24, 297-315. 


\section{Ethics Position Theory}

*Hadjistavropoulos, T., D. C. Malloy, D. Sharpe and S. Fuchs-Lacelle: 2003, 'The Ethical Ideologies of Psychologists and Physicians: A Preliminary Comparison', Ethics \& Behavior 13, 97-104.

^Henle, C. A., R. A. Giacalone and C. L. Jurkiewicz: 2005, 'The Role of Ethical Ideology in Workplace Deviance', Journal of Business Ethics 56, 219-230.

Hofstede, G.: 1980, Culture's Consequences: International Differences in Work-Related Values (Sage, Newbury Park, CA).

House, R. J. and M. Javidan: 2004, 'Overview of GLOBE', in R. J. House, P. J. Hanges, M. Javidan, P. W. Dorfman and V. Gupta (eds.), Culture, Leadership, and Organizations: The GLOBE Study of 62 Societies (Sage Publications, Thousand Oaks, CA), pp. 9-28.

Hunt, S. D. and S. J. Vitell: 1986, 'A General Theory of Marketing Ethics', Journal of Macromarketing 6, 5-16.

Hunt, S. D. and S. J. Vitell: 1993, 'The General Theory of Marketing Ethics: A Retrospective and Revision', in N.C. Smith and J.A. Quelch (eds.), Ethics in Marketing (Richard D. Irwin, Homewood, IL), pp. 775-784.

Inglehart, R.: 1997, Modernization and Postmodernization: Cultural, Economic, and Political Change in 43 Societies (Princeton University Press, Princeton, NJ).

Inglehart, R. and W. E. Baker: 2000, 'Modernization, Cultural Change, and the Persistence of Traditional Values', American Sociological Review 65, 19-51.

^Ishida, C.: 2006, 'How Do Scores of DIT and MJT differ? A Critical Assessment of the Use of Alternative Moral Development Scales in Studies of Business Ethics', Journal of Business Ethics 67, 63-74.

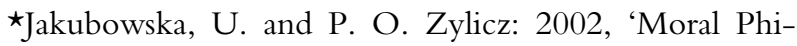
losophy of Political Extremists', Polish Psychological Bulletin 33, 13-18.

Kaikati, J. G., G. M. Sullivan, J. M. Virgo, T. R. Carr and K. S. Virgo: 2000, 'The Price of International Business Morality: Twenty Years Under the Foreign Corrupt Practices Act', Journal of Business Ethics 26, 213-222.

^Kaiser, D.: April, 1994, Ethical Ideology and Religious Problem-Solving Styles. Poster Presented at the Meeting of the Southwestern Psychological Association, Tulsa, OK.

^Karande, K., C. P. Rao and A. Singhapakdi: 2002, 'Moral Philosophies of Marketing Managers: A Comparison of American, Australian, and Malaysian Cultures', European Journal of Marketing 36, 768-792.

^Keyton, J. and S. C. Rhodes: 1997, 'Sexual Harassment: A Matter of Individual Ethics, Legal Definitions, or Organizational Policy?', Journal of Business Ethics 16, 129-146.

^Killen, A. R.: 2002, 'Morality in Perioperative Nurses', AORN Journal 43, 532-549.
^Kim, Y. W.: 2003, 'Ethical Standards and Ideology Among Korean Public Relations Practitioners', Journal of Business Ethics 42, 209-223.

*Kim, Y. and Y. Choi: 2003, 'Ethical Standards Appear to Change With Age and Ideology: A Survey of Practitioners', Public Relations Review 29, 79-89.

Koehn, D.: 1999, 'What Can Eastern Philosophy Teach Us About Business Ethics?', Journal of Business Ethics 19, 71-80.

Kohlberg, L.: 1976, 'Moral Stages and Moralization: The Cognitive-Developmental Approach to Moral Education', in T. Lickona (ed.), Moral Development and Behavior: Theory, Research and Social Issues (Holt, Rinehart and Winston, New York), pp. 31-53.

^Lawrence, J. E. and M. K. Shaub: 1997, 'The Ethical Construction of Auditors: An Examination of the Effects of Gender and Career Level', Managerial Finance 23, 52-68.

^Leary, M. R., P. D. Knight and B. D. Barnes: 1986, 'Ethical Ideologies of the Machiavellian', Personality and Social Psychology Bulletin 12, 75-80.

Lee, K. and M. C. Ashton: 2004, 'Psychometric Properties of the HEXACO Personality Inventory', Multivariate Behavioral Research 39, 329-358.

$\star$ Lee, D. and M. J. Sirgy: 1999, 'The Effect of Moral Philosophy and Ethnocentrism on Quality-of-Life Orientation in International Marketing: A Cross-Cultural Comparison', Journal of Business Ethics 18, 73-89.

MacKewn, A. S. and K. W. Van Vuren: 2007, Ethical Business Decision-Making: A Comprehensive Validation of Forsyth's Ethics Position Questionnaire. Paper Presented at the Academic Business World International Conference, Nashville, TN, US. Retrieved November 2, 2007, from http://abwic.org/ Proceedings/2007/DraftProceedings2007.pdf.

Marta, J. K. M., A. Attia, A. Singhapakdi and N. Atteya: 2003, 'A Comparison of Ethical Perceptions and Moral Philosophies of American and Egyptian Business Students', Teaching Business Ethics 7, 1-20.

«Marta, J. K. M., A. Singhapakdi, A. Attia and S. J. Vitell: 2004, 'Some Important Factors Underlying Ethical Decisions of Middle-Eastern Marketers', International Marketing Review 21, 53-67.

*McHoskey, J. W.: 1996, 'Authoritarianism and Ethical Ideology', Journal of Social Psychology 136, 709-717.

*Nebenzahl, I. D., E. D. Jaffe and B. Kavak: 2001, 'Consumers' Punishment and Rewarding Process Via Purchasing Behavior', Teaching Business Ethics 5, 283306.

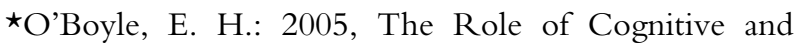
Affective Load on Moral Judgment. Unpublished Thesis, Virginia Commonwealth University, Richmond, VA. 
Donelson R. Forsyth et al.

^Park, H.: 2005, The Role of Idealism and Relativism as Dispositional Characteristics in the Socially Responsible Decision-Making Process', Journal of Business Ethics 56, 81-98.

Pelto, P.: 1968, 'The Difference Between 'Tight' and 'Loose' Societies', Transaction 5, 37-40.

*Peterson, D. K.: 2003, 'The Relationship Between Ethical Pressure, Relativistic Moral Beliefs and Organizational Commitment', Journal of Managerial Psychology 18, 557-572.

$\star$ Rawwas, M. Y. A.: 1996, 'Consumer Ethics: An Empirical Investigation of the Ethical Beliefs of Austrian Consumers', Journal of Business Ethics 15, 1009-1019.

^Rawwas, M. Y. A., G. L., Patzer and M. L. Klassen: 1995, 'Consumer Ethics in Cross-Cultural Settings: Entrepreneurial Implications', European Journal of Marketing 29, 62-78.

*Rawwas, M. Y. A. and A. Singhapakdi: 1998, 'Do Consumers' Ethical Beliefs Vary With Age? A Substantiation of Kohlberg's Typology In Marketing', Journal of Marketing Theory and Practice 6, 26-38.

^Rawwas, M. Y. A., Z. Swaidan and J. Al-Khatib: 2006, 'Does Religion Matter? A Comparison Study of the Ethical Beliefs of Marketing Students of Religious and Secular Universities in Japan', Journal of Business Ethics 65, 69-86.

^Rawwas, M. Y. A., Z. Swaidan and M. Oyman: 2005, 'Consumer Ethics: A Cross-Cultural Study of the Ethical Beliefs of Turkish and American Consumers', Journal of Business Ethics 57, 183-195.

^Rawwas, M. Y. A., S. J. Vitell and J. A. Al-Khatib: 1994, 'Consumer Ethics: The Possible Effects of Terrorism and Civil Unrest on the Ethical Values of Consumers', Journal of Business Ethics 13, 223-231.

Redfern, K.: 2004, 'An Empirical Investigation of the Ethics Position Questionnaire in the People's Republic of China', Journal of Business Ethics 50, 199210.

*Redfern, K.: 2005, 'The Influence of Industrialization on Ethical Ideology of Managers in the People's Republic of China', Cross Cultural Management 12, 3850 .

^Robertson, C. J., K. M. Gilley and M. D. Street: 2003, 'The Relationship Between Ethics and Firm Practices in Russia and the United States', Journal of World Business 38, 375-384.

Scholtens, B. and L. Dam: 2007, 'Cultural Values and International Differences in Business Ethics', Journal of Business Ethics 75, 273-284.

Schwarz, N.: 1999, 'Survey Methods', in D. T. Gilbert and S. T. Fiske (eds.), The Handbook of Social Psychology, 4th edition, Vol. 1 (McGraw-Hill, New York), pp. 143-179.
*Singhapakdi, A. and J. K. M. Marta: 2005, 'Comparing Marketing Students With Practitioners on Some Key Variables of Ethical Decisions', Marketing Education Review 15, 13-25.

Singhapakdi, A., J. K. Marta, K. C. Rallapalli and C. P. Rao: 2000, 'Toward an Understanding of Religiousness and Marketing Ethics: An Empirical Study', Journal of Business Ethics 27, 305-319.

*Singhapakdi, A., J. K. M. Marta, C. P. Rao and M. Cicic: 2001, 'Is Cross-Cultural Similarity an Indicator of Similar Marketing Ethics?', Journal of Business Ethics 32, 55-68.

*Singhapakdi, A., M.Y.A. Rawwas, J. K. Marta and M. I. Ahmed: 1999, 'A Cross-Cultural Study of Consumer Perceptions About Marketing Ethics', Journal of Consumer Marketing 16, 257-272.

*Singhapakdi, A., S. J. Vitell and O. Leelakulthanit: 1994, 'A Cross-Cultural Study of Moral Philosophies and Ethical Perceptions', International Marketing Review 11, 65-78.

*Siu, N., A. Hui and B. Lee: 2001, 'An Empirical Investigation of the Ethical Beliefs of Consumers in China', BRC Papers on China 1-30.

*Sommer, S. M., D. H. B. Welsh and B. L. Gubman: 2000, 'The Ethical Orientation of Russian Entrepreneurs', Applied Psychology: An International Review 49, 688-708.

*Steenhaut, S.: 2006, Towards a Better Understanding of Unethical Consumer Behavior: The Influence of Individual Characteristics, Situational Circumstances and Emotional Experiences in Consumers' Ethical Decision-Making Processes. Unpublished Doctoral Dissertation, Ghent University, Ghent, Netherlands.

*Suter, T. A., S. W. Kopp and D. M. Hardesty: 2006, 'The Effects of Consumers' Ethical Beliefs on Copying Behavior', Journal of Consumer Policy 29, 190-202.

Tan, B. L. B.: 2002, 'Researching Managerial Values: A Cross-Cultural Comparison', Journal of Business Research 55, 815-821.

*Treise, D., M. F. Weigold, J. Conna and H. Garrison: 1994, 'Ethics in Advertising: Ideological Correlates of Consumer Perceptions', Journal of Advertising 23, 59-69.

*Tsahuridu, E. E.: 2006, 'Anomie and Ethics at Work', Journal of Business Ethics 69, 163-174.

Tsai, M. and C. Shih: 2005, 'The Influences of Organizational and Personal Ethics on Role Conflict Among Marketing Managers: An Empirical Investigation', International Journal of Management 22, 54-61.

*Van Kenhove, P., I. Vermeir and S. Verniers: 2001, 'An Empirical Investigation of the Relationships Between Ethical Beliefs, Ethical Ideology, Political Preference and Need for Closure', Journal of Business Ethics 32, 347-361. 


\section{Ethics Position Theory}

Vandello, J. A. and D. Cohen: 1999, 'Patterns of Individualism and Collectivism Across the United States', Journal of Personality and Social Psychology 77, 279-292.

*Vitell, S. J., A. Bakir, J. G. P. Paolillo, E. R. Hidalgo, J. Ai-Khatib and M. Y. A. Rawwas: 2003, 'Ethical Judgments and Intentions: A Multinational Study of Marketing Professionals', Business Ethics: A European Review 12, 151-171.

*Vitell, S. J. and E. R. Hidalgo: 2006, 'The Impact of Corporate Ethical Values and Enforcement of Ethical Codes on the Perceived Importance of Ethics in Business: A Comparison of U.S. and Spanish Managers', Journal of Business Ethics 64, 31-43.

*Vitell, S. J., J. R. Lumpkin and M. Y. A. Rawwas: 1991, 'Consumer Ethics: An Investigation of the Ethical Beliefs of Elderly Customers', Journal of Business Ethics 10, 365-375.

Vitell, S. J. and J. G. P. Paolillo: 2003, 'Consumer Ethics: The Role of Religiosity', Journal of Business Ethics 46, 151-171.

Vitell, S. J., J. G. P. Paolillo and J. L. Thomas: 2003, 'The Perceived Role of Ethics and Social Responsibility: A Study of Marketing Professionals', Business Ethics Quarterly 13, 63-75.

^Watson, P. J., R. J. Morris, R. W. Hood, J. T. Milliron and N. L. Stutz: 1998, 'Religious Orientation, Identity, and the Quest for Meaning in Ethics Within an Ideological Surround', International Journal for the Psychology of Religion 8, 149-164.

*Wilson, M. S.: 2003, 'Social Dominance and Ethical Ideology: The End Justifies the Means?', The Journal of Social Psychology 143, 549-558.

*Winter, S. J., A. C. Stylianou and R. A. Giacalone: 2004, 'Individual Differences in the Acceptability of Unethical Information Technology Practices: The Case of Machiavellianism and Ethical Ideology', Journal of Business Ethics 54, 275-301.
Xing, F.: 1995, 'The Chinese Cultural Systems: Implications for Cross-Cultural Management', $S A M$ Advanced Management Journal 60, 14-20.

*Ziegenfuss, D. E.: 1999, 'Differences in Personal Ethical Philosophy Among Accounting Students and Between Accounting Students and Practitioners', Southern Business Review 25, 1-9.

*Ziegenfuss, D. E., A. Singhapadki and O. B. Martinson: 1994, 'Do Internal Auditors and Management Accountants Have Different Ethical Philosophies?', Managerial Auditing Journal 9, 4-12.

Donelson R. Forsyth Jepson School of Leadership Studies, University of Richmond, 28 Westhampton Way, Richmond, VA 23173, U.S.A. E-mail:dforsyth@richmond.edu

Ernest H. O'Boyle, Jr. and Michael A. McDaniel Virginia Commonwealth University, School of Business, Snead Hall, 301 W. Main Street, Richmond, VA 23284, U.S.A. 